\title{
Thoughts on How to Do a Good Job in Information Service of Postgraduate Entrance Examination from the Perspective of Medical Students*
}

\author{
Bian Pan \\ School of Medicine \\ Wuhan University of Science and Technology \\ Wuhan, China 430081
}

\author{
Yuchen Wang \\ School of Machinery and Automation \\ Wuhan University of Science and Technology \\ Wuhan, China 430081
}

\author{
Liangli Zhang \\ School of Information Science and Engineering \\ Wuhan University of Science and Technology \\ Wuhan, China 430081
}

\begin{abstract}
Because of the changes in professionalism and national policies, the postgraduate entrance examination for medical students has become an essential choice. Under the high rate of students taking part in the examination, due to the lack of information, a large number of medical students have to take the examination again in the next time, and much employment is not ideal. With damage to the students' own interests, the information service for postgraduate entrance examination (PG entrance exam) is particularly important. Through the discussion and questionnaire, we understand in this paper that the demand situation of clinical postgraduate students and collection problems of postgraduate entrance examination information, analyze the reasons of difficult information services, and put forward the corresponding implementing ways on how to improve the information service of PG entrance exam.
\end{abstract}

Keywords-medical students; postgraduate examination information; factor analysis; four in one

\section{INTRODUCTION}

MyCOS's 2017 Analysis Report on Employment of Chinese College Students released the distribution of nearly three college students. Among them, the graduate school rate was $8.9 \%$ in $2014,10.1 \%$ in $2015,10.3 \%$ in 2016, maintaining an upward trend. In all majors, the rate of medical students taking the PG entrance exam is the highest. In 2014, the Ministry of Education and the National Health and Family Planning Commission jointly issued Opinions on Deepening the Reform of Clinical Medical Talents Cultivation with Medical Education, the promulgation of which has changed the training mode of clinical specialties for "7 years" to "5 years +3 years ". It makes efforts to deepen education reform, improve the continuing education system and train qualified doctors. But it led to that the 5-year

*This research was financially supported by "Excellent Project on University Student affairs, Hubei, P.R.China (2017XGJPB3017)", and "Project on Humanities and Social Sciences of Educational Committee, Hubei, P.R.China (18Q025). undergraduate medical student can not directly go to medical school after graduation, and they need three years of standardized training. Undergraduates can only go to the local county-level hospitals when they choose to get a job. There is also a gap between the promotion of undergraduates and postgraduates after they have got the same physician's medical licenses. There is a huge gap between the high pay of medical students and the low achievement of reality, which makes the situation of medical undergraduates in our country more difficult. Therefore more medical undergraduates are devoting to the army of PG entrance exam.

There are two stages for medical students in medical training: theoretical study and clinical practice. At the time node of PG entrance exam, students are in the stage of internship, and there will be asymmetric information and blind review during the preparation period. And it may cause students' interests to be damaged, such as "second examination" and unsatisfactory employment. At present, many scholars mainly explore the internal causes [1] of PG entrance exam information services, single network information services [2], library construction [3], etc. From the perspective of students, there is rare analysis of PG entrance exam needs. On the basis of summarizing the existing research, taking Wuhan University of Science and Technology medical school as an example, the authors had field visits to six training practice bases, interview with students and deliver questionnaires, so as to make an analyze based on the needs of students for PG entrance exam. They also analyze the situation of schools, teachers, hospitals and candidates implementing the information service of $\mathrm{PG}$ entrance exam. 


\section{INFORMATION SERVICE DEMAND ANALYSIS OF PG ENTRANCE EXAM}

\section{A. Student Demand Survey}

From the process of PG entrance exam, the information is divided into register information, college information, tutor information, preparation information, and information of basic necessities of life. The latest recruitment information is usually published in the official website of enrollment unit from September to October of that year. And the published information is mainly based on the Speciality Catalog for Postgraduate Enrollment, but the contents are single, including only the introductions of colleges, reward policy and reference books of unified examination. Candidates can only refer to previous years' information in the process of preparing for the exam ahead of time. Each examinee needs to read a lot of paper media and collect electronic information on the Internet. It will cause a lot of waste of resources and time, and there will also be bias in information screening. At this time, the information service of $\mathrm{PG}$ entrance exam is particularly important.

Taking Wuhan University of Science and Technology as an example, this paper makes a detailed analysis of the needs and difficulties of clinical medical students, and explores a good solution. The way of investigation is to hold a face-toface communication in class meetings, and only to student interns outside. Assisted by self-made network questionnaire, the questionnaires distributed were filled in by the students from 2014 to 2017. The content of survey includes 16 questions, such as the way to obtain information, the way to review the examination, and the information service needed.

\section{B. Statistical Analysis of Results}

Through the face to face interviews with the graduates in 2014 who is an internship in Hanyang Hospital, Puren Hospital, Wuchang Hospital, Xiaogan Central Hospital and Tianyou Hospital. The interview results were summarized based on the internship bases in "Table I".

TABLE I. SUMMARY TABLE OF THE INTERVIEW RESULTS OF STUDENTS FROM SIX INTERNSHIP UNITS

\begin{tabular}{|l|l|l|}
\hline S/N & \multicolumn{1}{|c|}{ Problems } & \multicolumn{1}{|c|}{$\begin{array}{c}\text { Times of } \\
\text { Statistics }\end{array}$} \\
\hline 1 & $\begin{array}{l}\text { It is hoped to provide the special study room } \\
\text { and suspend the practice }\end{array}$ & 4 \\
\hline 2 & $\begin{array}{l}\text { The information is not sufficient, and selecting } \\
\text { school is not rational }\end{array}$ & 4 \\
\hline 3 & $\begin{array}{l}\text { The selection of review materials lacks } \\
\text { guidance, and the textbooks under the old } \\
\text { model are used }\end{array}$ & 2 \\
\hline 4 & $\begin{array}{l}\text { Information updated slowly is unable to } \\
\text { follow up the latest PG entrance exam policy }\end{array}$ & 5 \\
\hline 5 & $\begin{array}{l}\text { There was no interaction between school and } \\
\text { hospital, and no guidance in the review. }\end{array}$ & 2 \\
\hline
\end{tabular}

The interview results highlight the grim problem of information service for clinical students, mainly in the examination policies and lack of reference in school selection. Without affecting the time of clinical practice, it will inevitably lead to examinees will be rushed to choose schools and get into the review. Internship students outside cannot get effective information from schools or teachers. And the internship hospitals also take practice teaching as the main task and do not undertake information service. Even with the developed Internet, individuals are unable to get effective information in time because of limited energy time.

For the results of interviews, each question was refined and a questionnaire was produced. And the questionnaire was distributed to the grade groups of each class to find out the underlying reasons. 137 were recycled in the fifth grade, 54 were freshmen, 23 were sophomores, 71 were juniors, and 47 were seniors. A total of 332 questionnaires were collected, some statistics are shown in "Table II".

In the questionnaire, the students of freshmen and juniors were more involved. It can be seen that students are more concerned about information of postgraduate entrance exams when they enter school and face choices. The difficulty of information collection in clinical speciality is particularly prominent. In the questionnaires, $95.72 \%$ of the examinees indicated the difficulties, of which $40.81 \%$ said it was very difficult. The visible information collection is indeed a major problem for the PG entrance exam.

\section{TABLE II. QUESTIONNAIRE DATA STATISTICS}

\begin{tabular}{|c|c|c|c|}
\hline Items & $\begin{array}{c}\text { Proportion } \\
(\%)\end{array}$ & Items & $\begin{array}{c}\text { Proportion } \\
(\%)\end{array}$ \\
\hline $\begin{array}{l}\text { Major setting/ } \\
\text { minimum passing } \\
\text { score in target } \\
\text { college }\end{array}$ & 68.18 & $\begin{array}{l}\text { School lecture on PG } \\
\text { entrance exam }\end{array}$ & 35.36 \\
\hline $\begin{array}{l}\text { Accurate } \\
\text { professional } \\
\text { bibliography of } \\
\text { target college's } \\
\text { target major }\end{array}$ & 86.36 & $\begin{array}{l}\text { Free lectures from } \\
\text { research institutions }\end{array}$ & 18.18 \\
\hline $\begin{array}{l}\text { Notes of students } \\
\text { in target college's } \\
\text { target major }\end{array}$ & 31.82 & \begin{tabular}{lr} 
The & \multicolumn{2}{c}{ information } \\
known from & senior \\
schoolmates & or \\
teachers & \\
\end{tabular} & 68.18 \\
\hline \begin{tabular}{lr}
\multicolumn{2}{l}{ Tutor information } \\
about & target \\
college' & target \\
major &
\end{tabular} & 63.64 & $\begin{array}{l}\text { Comprehensive } \\
\text { education websites } \\
\text { (such as Graduate } \\
\text { Recruitment Network, } \\
\text { China Education } \\
\text { Online, etc.) }\end{array}$ & 50.00 \\
\hline $\begin{array}{l}\text { Enrollment ratio } \\
\text { of target college, } \\
\text { and elimination } \\
\text { rate of } \\
\text { reexamination }\end{array}$ & 4.55 & $\begin{array}{l}\text { The website, Weibo, } \\
\text { post bar and other } \\
\text { online communities of } \\
\text { the graduate school of } \\
\text { target college }\end{array}$ & 36.36 \\
\hline $\begin{array}{l}\text { Enrollment } \\
\text { policies of target } \\
\text { college }\end{array}$ & 31.82 & $\begin{array}{l}\text { PG entrance exam } \\
\text { APP, WeChat official } \\
\text { account, QQ }\end{array}$ & 10.37 \\
\hline
\end{tabular}

Through the investigation of information that examinees need mostly, review materials, target colleges, tutors and policies are the key points of students' concern. These information are common problems, but appear in a high proportion of medical students. So there must be a necessary connection with the means of student collection.

Where can the candidates get the PG entrance exam information? It is shown in the survey that $68.18 \%$ are from senior schoolmates or teachers, $50 \%$ from comprehensive education website and $36.36 \%$ from graduate websites of target colleges. And less information are from school lectures, 
apps and WeChat public accounts. It shows that the requirement of examination information for medical students tends to be more convenient, direct and accurate. In the network information age, the ways to acquire information on the Internet are less utilized.

Through the investigation of whether Internet access to postgraduate examination information is helpful to the decision of examinees, it is shown in the result that $18.18 \%$ is quite helpful, $40.91 \%$ is very helpful, and $40.91 \%$ is generally helpful. It shows that medical examinees still have a skeptical attitude towards the authenticity of network information which is difficult to be used. Under the background of medical specialty, schools should increase students' information network education.

According to the above data, schools, teachers and fulltime instructors are the key points for students to rely on. However, the postgraduate examination service is not satisfactory in schools. Not all information can be collected in the bookstore for the review information. In addition to preparing the required courses for their tutors, they should prepare two to three examinations with a unified proposition by the Ministry of Education, such as political theory, foreign language, etc. Because of the scattered and incomplete materials of these subjects, the examinees take a lot of energy for that. At this time, if you can provide timely and personalized information services for examinees, what a relief that is for them!

\section{THOUGHTS ON DIFFICULTIES OF OBTAINING} INFORMATION SERVICE FOR PG ENTRANCE EXAM

In the PG entrance exam, information collection is a very important step. For clinical students, it appears to be inadequate and narrow collection channels in the information collection. In addition to their own reasons, the analysis of external factors is also an important guarantee for doing a good job in the examination service.

\section{A. Traditional Information Service Construction Is Not Firm}

It is shown in the questionnaires that, as the carriers of students, schools and training hospitals play a small role in the service of examination. There are no special departments in universities to undertake information services. As the most basic information service center, a library is responsible for collecting, collating, preserving and transmitting documents and providing them for use. It undertakes only part of information service without special enquiry and consultation service. There is not enough attention to the enrollment catalogue of graduate students and course guidance materials which are not closely related to the library collection system, and to collecting and accumulating at ordinary times. There is no special person to carry out this work, not to collect and manage information on this examination into the normal work of library [4]. With the increase of demand for service in the examination and the obsolete library management mode, it is resulted in the information update cannot keep up with the pace of demand, and cannot meet the vast number of examinees' growing information needs of postgraduate examination. In colleges, there is no special information reading room, or related publicity columns to publicize the policies of colleges, adjustment of professional settings, change of examination outline and reform. Therefore, in order to solve the contradiction between supply and demand of PG entrance exam, the effective ways are to develop and build a traditional information service platform and strengthen the management.

\section{B. Insufficient Information in Network Information Service Platform}

Through the convenient and fast network platforms, we can get information at any time, participate in online interaction, meet information needs and save human resources and material resources. In the case of weak infrastructure, most of service information basically comes from the websites of examination institutions, websites of enrollment colleges, related information services websites, and WeChat official accounts. It is difficult to distinguish the genuine and fake information on the Internet, and most of the information is generalized information. For example, in the acquisition of tutor information, number of student enrollment, curriculum guidance and other specific information, as these information has a certain degree of internal parameters, they generally will not be used for open exchanges. Another part of information available on the Internet will cost a lot of money. At present, some colleges and universities have developed their own information service platform for the examination. But the construction of website is inadequate, and the inquired scope, depth and timeliness of information need to be improved. Simply speaking, medical students have different colleges and majors, so they need different information for different needs. If there is no good information platform construction, it is unable to play the role of guidance and assistance. [5].

\section{Lack of Information Linkage in Each Link of Education System}

In the construction of educational ecosystem, students are around with the nodes of school, teacher, hospital, government and society. Each node can provide specific PG entrance exam information service according to its own location. But each node is only one-way information transmission, there is no close contact between them and lack of mutual exchange and feedback. After the government's policy is transmitted to schools, it cannot be guaranteed whether teachers and students can know it in time, and whether the relationship between teachers and students is smooth. The hospital, school and government are in a state of disconnection. Some social organizations actively collect information from governments, schools, teachers, etc. based on their interests, and the transmission of information between students is based on interests. All links cannot be organically integrated and operated, and the transmission of information will be blocked. We can do nothing but renew the concept, reform the traditional service mode, and constantly explore and research new situations and new problems, so as to better serve the readers of $\mathrm{PG}$ entrance exam [6].

\section{IV. "FOUR IN ONE" TO IMPROVE INFORMATION SERVICE OF PG ENTRANCE EXAM}

Schools pay more attention to setting up service platforms Due to the limitations of school conditions and the school assessment mechanism, to a large extent, universities are 
neutral towards students' PG entrance exam. The freshmen and juniors in the questionnaire showed their willingness to take the PG entrance exam obviously. Considering the demand side of students, it is necessary for schools to set up platforms for education and information services, strengthen the education of PG entrance exam and network education for college students. When freshmen enter school, the schools shall put the education for PG entrance exam into the training plan, and improve students' self cognition through curriculum education. It is also necessary to guide students to self orientation, cultivate students' self planning ability, and make early study plan [7]. Secondly, in order to guarantee the construction of basic information services, the most basic way for schools is to increase the information construction of PG entrance examination. And the library shall ensure that the information of paper is abundant while increasing information service. And it is necessary to compile the enrollment guide and examination materials for each college according to the actual situation. And a fast way shall be provided to students for finding information and data through information media such as websites, WeChat and weibo. The library shall collate and summarize the information of graduate schools (admission line, reexamination line, tutor information, etc.), and strictly control the sending of information to ensure that the information description is true [8]. The school shall link graduate schools and colleges to create an atmosphere for postgraduate entrance examination, and build information service sites suitable for various majors. On the basis of professional features, the college shall organize lectures on PG entrance examination during the examination preparation to convey the professional policy changes, professional system adjustment, review methods, and how to balance practice and review to students, so as to avoid entering the minefield of PG entrance examination.

Teachers and counselors play a leading role. The counselors and teachers shall be guided as the most direct interaction partners with students, and they play an important role in students' study and PG entrance examination. They should promptly understand the information trend and provide advisory services to students with different needs. When the freshmen enter into the school, they should be screened and interviewed face-to-face. And it is necessary to accumulate consulting records, seize the information needs of students for PG entrance examination, and promote the method in lectures or teaching. As a professional course teacher, teachers should strengthen guidance in reviewing professional courses and make individualized guidance for students. For senior interns outside, we should organize seminars based on practice bases, bring information to hospitals, and provide guidance of school selection and policies. Taking students' school choice as an example, in the past years, there was a lot of students flocking together to one school and blind obedience. $33 \%$ of 12-grade students apply for Huazhong University of Science and Technology, and 34\% for Wuhan University; 36\%, of 13grade students apply for Huazhong University of Science and Technology, and 35\% for Wuhan University. After the guidance, it was shown in the 18-grade students' intention statistics that the distribution is relatively smooth and reasonable, which has an effective avoidance of conformity and the internal friction for the examination. In the information service of examination, teachers and counselors should not only instruct and help students in professional courses and policies, but also build a solid psychological fortress for students. The states of mind such as anxiety, helplessness and confusion, and other students' safety problems in the PG entrance examination, should be communicated transmitted to students in the information service. It is necessary to do a good job of tracking and protecting work to ensure students' physical and mental health.

When the hospital strengthens the information service and management practice, the internship hospital acts as the school role to manage the students. The hospitals should be linked with the school to set up the examination column, and set up the special reading room for the PG entrance examination. They should have a reasonable arrangement for student internships so as to facilitate the examination. The hospitals shall invite the experts and interns in the examination to give lectures in the hospital, share the experience, and guide the students to handle the contradiction between the examination and the internship. The hospitals should mobilize the enthusiasm of postgraduates trained by the internship unit. A successful postgraduate can form a one to one information assistance mechanism with examinees. The teachers in all departments of the hospitals are experienced experts who can provide professional guidance services for students. As the nearest unit to contact with students, hospitals should also undertake the psychological consultation work of students. They should keep abreast of the students' ideological trends, and create a PG entrance examination atmosphere with personal chat and discussion. We should also strengthen the management of these students, and [9] seriously deal with reducing an internship time by oneself.

Students play a positive role in their initiative. Schools, teachers, hospitals and so on are all passive collectors of PG entrance examination, and the students are the main body of the examination. Although medical students lack of insight and discernment in network information acquisition, they should exert their subjectivity in information collection, being active and enterprising. The preparation for the examination should be started ahead of schedule. It can be carried out through the traditional way, such as "a postgraduate enrollment guide of a medical college", an enrollment handbook, lectures, and even inquiries to teachers and seniors. The information can be collected from some information network modes, such as WeChat official account, an official website of college, related Apps, etc. In the collection process, students should pay attention to distinguish the true and false information, and select appropriate institutions through statistical analysis of information. They shall put an end to a "brain fever" to register for examination, but develop a good review plan, make reasonable arrangements for practice, so as to avoid blind review.

\section{CONCLUSION}

Because of their specialty and the policy requirements of "training qualified doctors", PG entrance examination has become a necessary choice for medical students. When other majors can arrange their own PG entrance exams 
independently, medical students can only work in their internship hospitals. Therefore, it is necessary to provide effective, real and direct information service for medical examinees facing choices. Based on field surveys and statistical questionnaires, this paper analyzes and explores the demand of medical examinees for the examination and the difficulties in information service. According to the actual situation of each link, the suggestion for carrying out the information service construction of PG entrance examination is put forward for the schools, practice bases, teachers and counselors, and examinees. And then a complete information service will be built for examinees to provide the latest information query, information consultation and information search as the reference in their decision-making. Through the above measures, it can be ensured that examinees can have a correct start and a choice in line with their own, so that they can devote themselves to the review of professional subjects without any harm the interests of themselves.

\section{REFERENCES}

[1] Yang Xiaojie. Research on Motivation and Management Mode of Postgraduate Entrance Examination for University Students [J]. Guide Journal of Science and Education (Midmonth Version), 2018(5):183 184.

[2] Gong Huiling, Wang Ling, Yu Zhicheng, etc. Application of WeChat Public Platform in Postgraduate Entrance Examination for Medical Students[J]. Inner Mongolia Science Technology and Economy, 2018(1):32 34.

[3] Song Tao. Inadequacy and Improvement of Information Service for Postgraduate Entrance Examination in University Libraries [J]. Knowledge and Encouragement, 2017(1).

[4] Li Yamei. Craze for Postgraduate Entrance Examination and Information Consultation Service, 2002,22(9):90-91.

[5] Feng Xiaoyun, Zhou Caixia, Kong Hao. Analysis on Status Quo of Clinical Postgraduate Entrance Examination in Private Medical Colleges -- Taking Qilu Medical College as an Example [J]. Value Engineering, 2017(10):153 154.

[6] Lin Guotian, Zhang Jingyin, Yang Yaying, etc. Anxiety and Influencing Factors of Postgraduate Entrance Examination for Medical Students[J]. Hainan Medical, 2018(11).

[7] Zhu Xiaowen. Guiding Undergraduates to Take the Postgraduate Entrance Examination to Promote Construction of Study Style[J]. Journal of Higher Learning Research, 2017(17):143-145.

[8] Wei Zhouyang, Chen Xingwu and Deng Yingxia. Investigation and Analysis of Clinical Practice, Postgraduate Entrance Examination and Employment of Medical Undergraduates[J]. Northwest Medical Education, 2015,(3):503 505.

[9] Li Ping, Ren Bailing and Wang Debin. Investigation and Countermeasures on Current Situation of Clinical Practice and Postgraduate Entrance Examination for Medical Undergraduates [J]. Anhui Medical Journal, 2011,(4):531 533. 